\title{
A intervenção do terapeuta ocupacional junto às pessoas-hospitalizadas: adotando a abordagem dos cuidados paliativos ${ }^{1}$
}

\author{
Andreia da Rosa Trevisana ${ }^{a}$ (D), Simone Reksua ${ }^{a}$ (D), Wagner Damian de Almeida ${ }^{a}$ (i), \\ Maria José Gugelmin de Camargo ${ }^{b}$ (i) \\ a'Universidade Federal do Paraná - UFPR, Curitiba, PR, Brasil. \\ bDepartamento de Terapia Ocupacional, Universidade Federal do Paraná - UFPR, Curitiba, PR, Brasil.
}

\begin{abstract}
Resumo: Introdução: Um dos maiores problemas de saúde no Brasil é a prevalência de doenças crônicas. A WHO sugere que pacientes com essas doenças recebam cuidados paliativos (CP) desde o diagnóstico. O terapeuta ocupacional pode colaborar no cuidado de pessoas hospitalizadas com ações que promovam dignidade e qualidade de vida ao paciente. Objetivos: Compreender a abordagem de cuidados paliativos adotada por terapeutas ocupacionais no cuidado de pessoas com doenças crônicas; e, conhecer a organização dos cuidados paliativos nos hospitais gerais de Curitiba. Método: É um estudo qualitativo cuja coleta de dados realizou-se através de entrevistas semiestruturadas gravadas para posterior transcrição, categorização, análise e discussão dos resultados. Para tratamento e análise dos dados, utilizou-se a técnica de análise de conteúdo. Resultados: Foram identificadas e discutidas as categorias: “cuidados paliativos nos hospitais gerais de Curitiba: organização do serviço" e "Intervenção do terapeuta ocupacional baseada na abordagem dos cuidados paliativos". Na primeira abrangeu-se a organização dos CP e as dificuldades enfrentadas pelas entrevistadas na prática dessa abordagem; na segunda, foram incluídas as avaliações utilizadas, objetivos e intervenções realizadas. Conclusão: Os relatos demonstraram que a abordagem estava associada à fase final da vida. O tipo de avaliação realizada dependia da organização do serviço de terapia ocupacional da instituição. Os objetivos das intervenções eram condizentes com os princípios dos CP. A realização de atividades significativas foi a principal intervenção citada e todas elas buscavam a promoção da qualidade de vida, bem-estar e manutenção da vida ativa.
\end{abstract}

Palavras-chave: Terapia Ocupacional, Cuidados Paliativos, Hospitalização.

\section{The occupational theraphy intervention with people in hospitalization using the paliative care aproach}

\begin{abstract}
Introduction: One of the worst issues of Brazilian public health is the prevalence of chronic diseases. The WHO suggests that patients who have these diseases should receive Palliative Care (PC) since the diagnostic. The occupational therapist can help in the cares of this hospitalized people, with actions which improve their life quality as well as dignity. Objectives: Comprehend the approach of PC adopted by occupational therapists on the care of hospitalized people with chronicle diseases and know about the structure of palliative care on Curitiba's General Hospitals. Method: It's a qualitative study which collects data from a semi-structured recorded interview for posterior transcription, categorization, analysis and discussion of the results. For the treatment and analysis of data a analysis of content technique was used. Results: It was identified and discussed these following categories: "Palliative Cares inside Curitiba's hospitals: service organization" and "The occupational therapist intervention based in the Palliative Care approach". In the first one the organizations and the struggle that the interviewers have based in this approach experience were included; the second one included the assessments used, objectives and
\end{abstract}

Autor para correspondência: Maria José Gugelmin de Camargo, Universidade Federal do Paraná, Av. Prefeito Lothário Meissner, 632, Jardim Botânico, CEP 80210-170, Curitiba, PR, Brasil, e-mail: mariajosegugelmin@hotmail.com

Recebido em Set. 30, 2017; $1^{\text {a }}$ Revisão em Jun. 11, 2018; 2ª Revisão em Set. 18, 2018; Aceito em Out. 31, 2018.

Este é um artigo publicado em acesso aberto (Open Access) sob a licença Creative Commons Attribution, que permite uso, distribuição e reprodução em qualquer meio, sem restrições desde que o trabalho original seja corretamente citado. 
interventions performed. Conclusion: The reports show that the approach was associated with life's final stage. The type of assessment realized depended on the organization of the institution occupational therapy service. The objectives of the interventions were in keeping with the PC principles. The execution of significant activities was the main related intervention and all of them looked for the improvement of life quality, well being and active life conservation.

Keywords: Occupational Therapy, Palliative Care, Hospitalization.

\section{Introdução}

Atualmente, um dos maiores problemas de saúde pública no Brasil é a prevalência de doenças crônicas, que correspondem a um grande número de internaçóes e estão entre as principais causas de amputações, perdas de mobilidade e disfunções neurológicas (BRASIL, 2015).

Muitas pessoas com doenças crônicas têm a continuidade da vida ameaçada e sofrem de sintomas e desconfortos que afetam sua qualidade de vida. Tratamentos curativos não surtem efeitos em inúmeros casos, os quais requerem a atenção de uma equipe cuja prática esteja pautada nos cuidados paliativos (ACADEMIA..., 2006). A Academia Nacional de Cuidados Paliativos (2006) estima que mil pacientes, ao ano, para cada grupo de um milhão de habitantes, necessitam desses cuidados. Isso significa que, em 2015, um total de 205 mil brasileiros atendiam a critérios de inclusão em CP (INSTITUTO..., 2013).

\section{Segundo a World Health Organization:}

Os cuidados paliativos são uma abordagem que melhora a qualidade de vida dos pacientes (adultos e crianças) e suas famílias que enfrentam problemas associados a doenças potencialmente fatais. Previne e alivia o sofrimento através da identificação precoce, avaliação correta e tratamento da dor e outros problemas, sejam eles físicos, psicossociais ou espirituais (WORLD..., 2018, não paginado, tradução livre).

Othero e Costa (2014) referem os princípios que norteiam essa abordagem, com base na WHO, conforme segue: garantir o alívio da dor e de outros sintomas desconfortáveis e causadores de sofrimento; oferecer suporte para ajudar as pessoas a viverem táo ativamente quanto possível até a morte; integrar as dimensóes psicológicas e espirituais dos cuidados; melhorar a qualidade, podendo influenciar positivamente o curso da doença; afirmar a vida e considerar a morte um processo normal - a sua intenção não é, nem apressar, nem adiar a morte; oferecer um sistema de suporte aos familiares para auxiliá-los a lidar com a doença do paciente e com o período de luto; utilizar uma abordagem em equipe multiprofissional para responder às necessidades dos pacientes e de seus familiares, inclusive acompanhando-os durante o período do luto, quando necessário.

Arantes (2012) esclarece que a WHO recomenda o cuidado com base nessa filosofia, desde o seu diagnóstico, para todos os pacientes portadores de doenças graves, progressivas, incuráveis e ameaçadoras da continuidade da vida. Todavia, menciona essa autora, a falta de profissionais e serviços para suprir a demanda inviabiliza a efetividade dessa recomendação. Assim sendo, a autora refere que a ANCP estabelece parâmetros que norteiam a inclusão do paciente no programa de cuidados paliativos, com o intuito de abranger principalmente a pessoa cuja possibilidade de tratamento ou manutençáo da vida seja remota; que apresenta sofrimento de moderado a intenso; e, optou pela manutenção do conforto e a dignidade da vida.

A Worldwide Palliative Care Alliance (WORLDWIDE..., 2014) - Aliança Mundial de Alívio Paliativo - no documento "Atlas Global de cuidados paliativos no Final da Vida" indica o nível de desenvolvimento em cuidados paliativos no qual se encontra um país, conforme critérios da WHO. Nesse documento, a WPCA reconhece 6 grupos de países reunidos conforme a oferta e a organização da assistência prestada. No primeiro grupo (Group 1) encontram-se países como Afeganistão, Somália e Iêmen, cujo nível de assistência é precário, ou seja, não apresentam atividade paliativas conhecidas. No sexto e último grupo (Group 4b) estão países como Austrália, Canadá, França e Japão que oferecem cuidados paliativos em fase avançada, ou seja, de forma generalizada e integrados aos demais serviços da rede. O Brasil, juntamente com Iraque, Nigéria e Venezuela, dentre outros países, integra o terceiro grupo (Group 3a) onde esses cuidados são disponibilizados de maneira isolada e não integrados à rede de assistência.

A classificação do Brasil na escala da WPCA evidencia a necessidade de os profissionais da saúde aprofundarem-se no tema para fundamentarem suas práticas e as orientarem segundo os princípios dessa filosofia e fim de pleitearem junto ao poder público 
e às instituiçốes onde atuam, a oferta dos cuidados paliativos de maneira estruturada e articulada a todos os níveis de atenção à saúde.

Conforme apontam De Carlo, Queiroz e Santos (2008), os cuidados paliativos devem ser implementados por equipe interdisciplinar e multiprofissional na qual o terapeuta ocupacional tem muito a contribuir para o alívio da dor e diminuição do sofrimento de pacientes e familiares, especialmente em processos de adoecimento e hospitalização. Contudo, inexistindo equipe especializada, o contexto hospitalar demanda que o terapeuta ocupacional esteja preparado para realizar açôes paliativas.

Ações paliativas podem ser realizadas por qualquer profissional da saúde e são definidas como medidas terapêuticas que não visam cura, mas reduzir repercussóes negativas de doenças clinicamente irreversíveis ou crônicas progressivas sobre o bem-estar da pessoa. Essas açôes podem ser isoladas, fazerem parte do cuidado desde a atenção básica e estarem presentes em qualquer etapa do adoecimento (ACADEMIA..., 2006; MACIEL, 2008; MACIEL, 2014).

\section{Objetivos}

Compreender a abordagem de cuidados paliativos adotada por terapeutas ocupacionais no cuidado de pessoas com doenças crônicas; e, conhecer a organização dos cuidados paliativos nos hospitais gerais de Curitiba.

\section{Método}

Trata-se de estudo de natureza qualitativa, porquanto fundamentado na compreensão fenomenológica da unidade de estudo a partir da vivência e interpretaçáo dos participantes, acreditando na conexão dinâmica entre eles e a realidade, ou seja, na intrínseca relação entre mundo objetivo e a subjetividade do participante (SANTOS, 2010).

A unidade analisada, nas palavras de Fonseca (2002) pode ser "[...] um programa, uma instituição, um sistema educativo, uma pessoa, ou uma unidade social" (FONSECA, 2002, p. 33). A unidade analisada neste estudo foi a população de terapeutas ocupacionais que trabalhou em hospitais gerais de Curitiba, por qualquer tempo, considerando-se o período entre $01 / 01 / 2015$ a 31/12/2016, e realizaram intervençóes com pessoas hospitalizadas, orientadas pelos princípios dos cuidados paliativos.

Inicialmente, em consulta ao "Cadastro Nacional de Estabelecimentos de Saúde (CNES)", foram identificados 42 estabelecimentos cadastrados como hospital geral, em Curitiba. Desses, conforme dados do CNES, somente 08 tiveram terapeutas ocupacionais em suas equipes no período considerado (BRASIL, 2016). Concluído esse levantamento, os terapeutas ocupacionais foram contatados, por meio de redes sociais ou telefonema, a fim de se identificar os que haviam trabalhado em unidades de internação hospitalar. Restaram, então, apenas 03 hospitais gerais cujos terapeutas ocupacionais atendiam ao critério estabelecido.

O critério de inclusão observado foi a afirmação, por parte dos terapeutas ocupacionais, de terem vivenciado a prática em cuidados paliativos, na assistência de pessoas hospitalizadas com doenças crônicas. Foram excluídos da amostra os profissionais que afirmaram não terem utilizado tal abordagem.

A pesquisa teve início após a aprovação e autorização do Comitê de Ética em Pesquisa da Universidade Federal do Paraná, parecer no 2.033.924. Os aspectos contidos na Resolução CNS 466/12 foram respeitados, assegurando-se os direitos dos participantes que assinaram o Termo de Consentimento Livre e Esclarecido (TCLE) e responderam a entrevista semiestruturada individual com quatorze questóes, respeitando-se data, horário e local, estabelecido pelo terapeuta ocupacional.

De acordo com Fonseca (2002), a entrevista semiestruturada permite que objetivos específicos sejam alcançados a partir de um roteiro definido que, entretanto, não é inflexível quanto à forma de conduçáo da conversa, o modo ou a ordem de formulaçáo das perguntas. Esse instrumento de coleta de dados passou por estudo piloto com duas terapeutas ocupacionais, sofrendo as modificaçóes sugeridas nesta etapa. As entrevistas duraram em média quarenta minutos e foram gravadas para transcriçãao, categorização, análise de conteúdo e discussão dos resultados.

Para tratamento e análise dos dados coletados, utilizou-se a técnica de análise de conteúdo temática, conforme propóe Bardin (2011). A autora ensina que na pesquisa qualitativa a análise de conteúdo privilegia a qualificação das vivências dos participantes, assim como suas percepçóes referentes ao objeto pesquisado e seus fenômenos. Essa técnica permite ao pesquisador a classificação das falas dos entrevistados em categorias de conteúdos significativos. De acordo com este enfoque, pode-se inferir uma versão teórica para explicar a realidade, ou ainda, oferecer uma referência para a ação, decorrentes da análise e discussão dos resultados (ROESCH, 1996). 
Após a coleta de dados foram realizadas as três fases fundamentais da análise de conteúdo, quais sejam: pré-análise; exploração do material; e, por fim, o tratamento dos resultados.

$\mathrm{Na}$ fase de pré-análise as entrevistas foram transcritas, constituindo-se o corpo da pesquisa. A identidade das participantes foi mantida em sigilo, sendo utilizados os termos TO $1,2,3,[\ldots]$ para identificação dos relatos. A numeração atribuída às entrevistadas foi definida aleatoriamente através de sorteio realizado pelos pesquisadores. Faz parte desse momento a "leitura flutuante", considerada ponto de partida para as interpretaçôes. A "leitura flutuante" proporciona aos pesquisadores o conhecimento do material coletado e familiarização com o conteúdo das entrevistas, ideias, pensamentos e posicionamentos. Na pré-análise, conforme Bardin (2011) foram obedecidas as regras de: exaustividade da comunicação; representatividade da amostra; homogeneidade com relação ao tema e forma de coleta dos dados; pertinência do conteúdo das entrevistas aos objetivos da pesquisa; e, exclusividade, ou seja, os elementos semânticos foram classificados em um único tema.

Com a certeza da suficiência do material, iniciou-se a segunda etapa proposta por Bardin (2011): "exploração do material". Essa fase consiste na organização dos dados que, agrupados por semelhança e inter-relaçóes de conteúdo, possibilitou a categorização do material.

Definidas as categorias, efetuou-se o terceiro momento da análise de conteúdo: "tratamento dos resultados". Nessa última etapa, o estudo cuidadoso dos dados permitiu que fossem realizadas inferências aos relatos das participantes, que levam a interpretaçóes dos dados posteriormente respaldados teoricamente.

\section{Resultados e Discussões}

Participaram da pesquisa 14 terapeutas ocupacionais, porém 01 entrevista foi descartada por não atender aos critérios de inclusão. Todas as participantes incluídas na pesquisa $(\mathrm{N}=13)$ são do sexo feminino, com média de idade de 31,8 anos. Quanto ao vínculo empregatício, 61,5\% ( $\mathrm{N}=8)$ eram residentes e $38,4 \%(\mathrm{~N}=5)$ estatutárias ou celetistas. Com relação à formação, $76,9 \%(\mathrm{~N}=10)$ concluíram a graduação na Universidade Federal do Paraná; $15,3 \%(\mathrm{~N}=2)$ na Universidade Federal de São Carlos; e 7,6\% (N=1) na Pontifícia Universidade Católica de Campinas. Nenhuma delas cursou a disciplina específica de cuidados paliativos, mas $84,6 \%(\mathrm{~N}=11)$ mencionaram terem discutido a abordagem em disciplinas curriculares, enquanto
$15,3 \%(\mathrm{~N}=2)$ sequer tiveram contato com o tema durante a formação profissional.

Da análise e interpretação dos depoimentos e relatos emergiram duas categorias: 1) "cuidados paliativos nos hospitais gerais de Curitiba: organização do serviço"; 2) "Intervenção do terapeuta ocupacional baseada na abordagem dos cuidados paliativos". Essas categorias serão discutidas a seguir.

\subsection{Categoria 1: cuidados paliativos nos Hospitais Gerais de Curitiba: organização do serviço}

Esta categoria abrange a organização do serviço de cuidados paliativos nos hospitais e as dificuldades enfrentadas pelas participantes na intervenção terapêutica ocupacional com base nessa abordagem.

Nenhum dos três hospitais com terapeutas ocupacionais, trabalhando na modalidade de internação, possuía equipe específica de cuidados paliativos. Somente a enfermaria de Clínica Médica de 01 dessas instituiçóes possuía leitos exclusivos, destinados a pessoas em cuidados de fim de vida, conforme referiu a profissional TO3:

\section{Agora, aqui [...] tem alguns leitos, né, que foram abertos exclusivamente para cuidados paliativos. [...] pelo que a gente está percebendo na prática, é um leito de cuidados terminais de vida, então (não) nessa perspectiva mais ampla de cuidados paliativos (TO3).}

Todas as práticas mencionadas seguiam essa linha, ou seja, estavam invariavelmente relacionadas aos últimos dias ou semanas quando o desencadeamento do processo do morrer é clinicamente perceptível. Entretanto, WHO defende que a intervenção em cuidados paliativos deve seguir o critério da necessidade e exige início precoce, bem antes do estágio terminal, independente do diagnóstico e prognóstico (WORLDWIDE..., 2014).

Ao serem questionadas se consideravam pertinentes a criação de uma unidade para esse tipo de assistência, as opiniōes diversificaram-se. A TO13 e outras seis participantes defenderam que uma unidade separada seria ideal porque exigiria uma equipe exclusiva:

Talvez deveria ser um lugar isolado, uma unidade separada, né, com uma equipe toda preparada pra isso (TO13).

Ao contrário, na perspectiva da TO3 e TO9 um local isolado ou serviço específico daria margem à discriminação, pois além de um ambiente psíquico 
desagradável uma unidade poderia ser compreendida apenas como espaço de morte:

Eu acho que uma unidade de cuidados paliativos ou um serviço de cuidados paliativos pode até ser um fator, às vezes, estigmatizante no sentido de que quem está lá, naquela unidade, não tem mais expectativa (TO3).

Uma unidade só de cuidados paliativos, eu acho que seria um clima muito pesado, tipo, ficar com aquele estigma: 'Ah, eu tô indo pra lá porque eu vou morrer (TO9).

A assistência por meio de uma equipe itinerante foi sugerida pela TO9. Segundo esse modelo o médico teria a opção de permanecer acompanhando seu paciente, mas a equipe especializada assumiria a coordenaçáo do caso:

Não sei se uma unidade fisica, mas uma equipe de cuidados paliativos que pudesse acompanhar esses pacientes nas unidades deles mesmos. Isso seria muito bom, se tivesse uma equipe exclusiva de cuidados paliativos que entendesse o que é, e pra acompanhar esses pacientes (TO9).

A TO3 levantou a hipótese de uma equipe consultora que ofereceria suporte e orientação às demais equipes do hospital, sem assumir a coordenaçáo do cuidado ao paciente:

[...] talvez, uma equipe de cuidados paliativos do hospital como um todo, que possa avaliar e treinar a equipe quando é necessário (TO3).

Porém, a mesma participante (TO3) defendeu o treinamento de todas as equipes de unidades/ serviços/enfermarias com pessoas sujeitas aos cuidados paliativos. Sua justificativa pareceu mais alinhada a Política Nacional de Humanização (PNH), ao privilegiar o vínculo terapêutico:

Eu acho mais interessante a ideia de que aqueles serviços que têm características, né, de doenças complexas, ameaçadoras da vida, tenham uma equipe preparada pra fornecer e oferecer esse Cuidado Paliativo, com vínculo. Ele (o paciente) já tá tratando desde sempre naquela unidade, então o profissional já conhece a história, já conhece a familia, não tem que fazer várias reavaliaçôes (TO3).

Para quatro das entrevistadas, no entanto, a forma como os cuidados paliativos deveriam ser organizados era menos relevante que sua efetiva oferta, por profissionais capacitados. Assim expressou a TO5:

Tô pensando na estrutura do serviço, mas com certeza precisaria ser estruturado ou uma unidade ou um serviço que fosse itinerário, mas que tivessem profissionais formados especificamente para cuidar dessas pessoas [...] (TO5).

Rodrigues (2012) discorre que no Brasil os cuidados paliativos se desenvolveram nos hospitais, organizados de três formas: a) unidade de cuidados paliativos com leitos em área definida e equipe capacitada para trabalhar com a abordagem, que pode fazer parte das dependências internas do hospital ou estar fisicamente separada da estrutura central; b) equipe consultora ou volante que oferece suporte às demais equipes do hospital e orienta condutas sem assumir a coordenaçáa do cuidado; c) equipe itinerante, requisitada pelo médico que decide se acompanhará o paciente, mas cuja coordenação passa a ser da equipe. Nos modelos " $b$ " e "c" não existem leitos específicos de cuidados paliativos, as pessoas permanecem nas enfermarias onde foram internadas.

Conforme Rodrigues (2012), unidades exclusivas de cuidados paliativos possuem como vantagem o trabalho coeso da equipe, cuja expertise pode melhorar a assistência ao paciente. Em termos de desvantagem menciona que as pessoas podem concluir, equivocadamente, que são destinadas apenas a pessoas em fim de vida (com expectativa de vida inferior a seis meses) e por esse motivo podem ser estigmatizadas como "local de morte". Percebe-se, portanto, que o autor corrobora tanto aspectos positivos quanto negativos mencionados por algumas entrevistadas.

O serviço estruturado através de uma equipe consultora ou itinerante, para Rodrigues (2012), possuem as mesmas vantagens e desvantagens. Ambas têm papel educador, além de disseminar rapidamente os princípios da filosofia devido ao frequente contato com outras equipes do hospital. Nesse sentido, o autor aproxima-se da hipótese levantada pelas TO3 e TO9. Porém, como aspecto negativo desse formato, aponta que a equipe consultora precisa trabalhar com profissionais sem conhecimentos adequados referentes à abordagem, $\mathrm{o}$ que pode dificultar a aceitação de alguns princípios e demandar maior tempo para adaptaçóes.

Rodrigues (2012) adverte, ainda, para um aspecto negativo adicional dos serviços com equipes específicas, qual seja, a possibilidade de os demais profissionais se posicionarem em zona de conforto e náo se envolverem nos cuidados paliativos. A proposta da TO3 descartou essa preocupação, pois envolveu o treinamento e protagonismo de todos os profissionais envolvidos no cuidado de pessoas com doenças ameaçadoras da vida. 
A diversidade de concepçóes acerca da melhor estrutura a ser adotada pode indicar tanto a necessidade de aprofundamento acerca do tema, quanto a falta de espaço para discussão nessas instituiçôes.

Questionadas acerca das dificuldades em prestar assistência terapêutico ocupacional em Cuidados Paliativos, todas as entrevistadas realçaram a falta de estrutura desse serviço como importante limitaçáo à prática. E, relativo ao processo de trabalho em suas instituiçôes, ficou evidente que as equipes multiprofissionais apresentavam pouca interdisciplinaridade e nenhuma transdisciplinaridade. Esse panorama revelou intervençôes por meio de ações paliativas, de acordo com o exemplo mencionado pela TO11:

Eu sei que as pessoas que trabalham aqui, em alguns momentos têm uma abordagem de cuidados paliativos, mas não uma equipe que vá realmente sentar e vá fazer isso. Específico, não. [...] A abordagem em cuidados paliativos é mais a conversa entre os profissionais que tem essa visão. Não tem uma estruturação assim, pra isso nesse trabalho aqui (TO11).

Nesse mesmo sentido a TO3 comentou:

É muito difícil a gente conseguir fazer um plano de cuidados paliativos porque vai depender da instituição, do modelo teórico da equipe que você integra, mas açóes paliativas a gente consegue fazer.

Eu acho que a partir do momento que o paciente fica afastado do cotidiano dele, impedido de ter contato com atividades, pessoas que säo significativas, $e$ (com) uma doença que é ameaçadora da vida, eu acho que a gente já pode ter açôes paliativas, né.

Ao explicarem, ainda sobre o processo de trabalho, algumas participantes mencionaram profissionais de outras áreas que prestavam assistência aos pacientes em cuidados paliativos. A TO13 referiu:

Então tinha o médico, o médico residente. A questão da enfermagem era mais geral, que é do setor mesmo, não era especifica dos cuidados paliativos. A nutrição, a fisioterapia, a psicologia e farmácia, era só pedido de consulta, então não era específico dos cuidados paliativos. A gente fazia diversas reuniōes, na época que eu passei. Alguns atendimentos a gente fazia de forma interdisciplinar, então a gente atendia junto, a gente conversava pra ter objetivos em comum, pra que esse paciente ganhasse mais. Trans (transdisciplinar) eu não sei se daria pra falar, mas inter (interdisciplinar) $a$ gente trabalha, sim (TO13).
A TO7, apesar de ter-se reportado ao mesmo setor de trabalho da TO13, descreveu um processo de trabalho com menor interação entre os profissionais da equipe:

[...] A gente conseguia fazer um atendimento só multiprofissional. Raramente, a gente tinha intervençōes interdisciplinar, principalmente com a fisioterapia, né, mas era muito raro porque a rotina não permitia que isso acontecesse (TO7).

As entrevistadas TO13 e TO7 trabalharam no mesmo setor, porém em épocas diferentes. Isso pode ter desencadeado percepçóes distintas, mas provavelmente sugere o quanto as pessoas que fazem parte da equipe influenciam no modo como se desenvolve o processo de trabalho.

As TO1, TO9 e TO10 destacaram como dificuldade o fato de o trabalho estar centrado na figura do médico:

Normalmente, a partir da discussäo dos casos ou visitas aos leitos, o médico geriatra, o médico responsável, definia com a família sobre se deve investir ou não nos cuidados, caso o paciente piorasse. E, a partir, eu acho, dessa conversa, dessa visita, depois a conversa entre todos os profissionais também, ai era repassado pra equipe. Mas assim, não existia uma construção no sentido de: "E agora, o que a gente pode fazer por esse paciente?!"Era mais no sentido: $O$, não reanimar; morfina se dor; $e$ enfim [...] (TO1).

Então, lá é um médico que paliativa o paciente, junto com a familia. [...] Ai os outros profissionais vão atuando, mas cada um ali na sua especificidade [...] (TO9).

[...] Eu acho que existem várias equipes e médicos diferentes, né. Eu acho que o que toma o rumo, principalmente, é a cultura do médico que tá naquele caso. Se o médico que tá naquele caso acredita em cuidados paliativos, ele faz com que toda a equipe acabe trabalhando nesse sentido. Se aquele médico não acredita em cuidados paliativos ou não sabe direito o que significa cuidados paliativos, eu acho que toda a equipe acaba sendo influenciada (TO10).

Para Nunes (2012) a compreensão do sofrimento global da pessoa com doença potencialmente letal é o que fundamenta a importância da intervençáo de uma equipe multiprofissional. A autora esclarece que dessa maneira o sofrimento é abordado conforme perspectivas específicas às expertises de cada profissional, com foco no paciente, família/cuidador e, até mesmo na própria equipe, que têm suas 
diferentes necessidades reconhecidas e atendidas por meio de açôes articuladas.

Maciel (2014) corrobora o entendimento dessa autora e defende que todas as açôes e decisôes sejam compartilhadas entre paciente, família e equipe de saúde, cotidianamente, especialmente na fase final da vida, a fim de serem evitadas avaliaçóes precipitadas e decisóes unilaterais, questionando a centralização do saber nas mãos do médico. Maciel (2014, p. 56) leciona: "Todos os profissionais têm a mesma importância no cuidado e na tentativa de dar conta de tantas necessidades".

Em síntese, verificou-se que muito embora as terapeutas ocupacionais tenham integrado equipes multiprofissionais, os cuidados paliativos raramente eram desenvolvidos a partir do trabalho de ações articuladas. Isso dependia basicamente: da estrutura do serviço; visão dos demais profissionais acerca dos cuidados paliativos; e/ou, de acordo com as especificidades de cada caso. Ademais, algumas falas assinalaram que a conversa do médico com os profissionais ocorria com intuito de repasse de orientações clínicas e demais decisóes, não para alinhamento de condutas. Tal comportamento denota que o médico assumia, com frequência, papel hierarquicamente superior. Portanto, em termos de processo de trabalho, a teoria se afasta consideravelmente das vivências descritas.

As barreiras enfrentadas pelas entrevistadas foram além desses aspectos. O desconhecimento dos demais profissionais acerca da terapia ocupacional foi registrado no desabafo da TO1:

Eu acho que a principal dificuldade que talvez os terapeutas ocupacionais tenham em todas as áreas, ainda é o desconhecimento da profissão. É você ter que tá o tempo todo mostrando, defendendo, $e$ argumentando, e disputando o teu espaço, porque isso não é de conhecimento geral da população, inclusive dos profissionais da saúde (TO1).

Silva e Othero (2010) ressaltam que a falta de conhecimento sobre a atuação do terapeuta ocupacional, é uma das dificuldades do desenvolvimento de um trabalho e reforçam a concepção das participantes ao lecionarem que o desconhecimento de outros profissionais da equipe, bem como da gerência do serviço, referente a especificidade, atribuiçóes e possibilidades de açóes conjuntas.

Emmel e Kato (2004) consideram que relativamente a outras profissóes da saúde, formam-se poucos profissionais de terapia ocupacional por ano no Brasil. Para as autoras, uma profissão é reconhecida socialmente quando, além de profissionais competentes e oportunidades de atuação em espaços diversificados, há representação significativa da categoria. De fato, o terapeuta ocupacional náo atingiu grande representatividade, o que talvez explique o desconhecimento de outros profissionais sobre seu papel e dificulte seu reconhecimento pessoal, assim como de suas açóes, no ambiente hospitalar.

As discordâncias e o desconhecimento acerca dos conceitos e princípios fundamentais da filosofia dos Cuidados Paliativos, também foram apontados como dificuldades da prática, conforme traduziram a TO3 e a TO 7:

\section{Acho que não tem um consenso entre a equipe, também, sobre pacientes em cuidados paliativos, no sentido de que você não deve mais fazer nada que seja curativo, né. Então, eu acho que a equipe náo consegue entrar num consenso e acaba tendo objetivos diferentes (TO3). \\ A gente conseguia, apesar de ter esse setor que eles não sabiam direito o que era cuidados paliativos e a gente entrava em discussão em vários momentos [...] (TO7).}

A falta de consenso acerca de conceitos e princípios básicos dos cuidados paliativos, provavelmente, deve-se ao déficit na formação dos profissionais, pois pesquisadores de outras áreas da saúde também relatam o mesmo problema e defendem o aprofundamento do tema na graduação (PARANHOS, 2016; PINHEIRO, 2010; VASQUES et al., 2014).

A falta de recursos e as restriçôes do ambiente físico no hospital também apareceram como limitaçôes. A TO1 mencionou:

O recurso zero, né [...]. O recurso, assim, era lápis de cor e coisas de doação que a gente ia recebendo".

Já a TO10 complementou:

O hospital, a gente não consegue muito trazer coisas do ambiente dos pacientes, por exemplo, da casa do paciente ali, ou mudar o ambiente hospitalar pra deixar ele um pouco mais acolhedor pro paciente, porque tem várias restriçōes. Restriçōes por causa de bactérias; restrição porque você não pode mudar, conforme é ali o ambiente, o ambiente fisico mais (TO10).

Silva e Othero (2010) ratificam o depoimento das entrevistadas, pois mencionam a falta de espaço físico e recursos materiais disponíveis para o trabalho como barreiras para a atuação do terapeuta ocupacional em cuidados paliativos. 


\subsection{Categoria 2: Intervenção do terapeuta ocupacional segundo abordagem dos cuidados paliativos}

Esta categoria abrange as avaliaçóes utilizadas, bem como objetivos e intervençôes realizadas como parte da abordagem dos cuidados paliativos.

Para Mello et al. (2004), o terapeuta ocupacional, através das técnicas e recursos avaliativos pretende: identificar o grau de autonomia e independência do paciente nas áreas de desempenho ocupacional no contexto hospitalar; elencar as dificuldades vivenciadas pelo processo de adoecimento e hospitalização; e, colaborar com informaçóes inerentes ao diagnóstico.

O processo avaliativo deve favorecer o conhecimento acerca do indivíduo a partir de sua história de vida, valores culturais e espirituais, interesses e cotidiano, atividades significativas e condiçôes ambientais onde vive. Além disso, devem ser observadas suas condiçôes físicas e emocionais e considerada a rotina hospitalar, que pode influenciar em suas expectativas e ansiedade quanto a diagnóstico e procedimentos (MELLO et al., 2004). Têm-se no exposto, corroboradas as palavras da TO3:

[...] Então, a entrevista e a avaliação vai no sentido de conhecer o histórico ocupacional, seja do adulto, seja da criança, né; entender os principais papéis ocupacionais que ele realizava antes da hospitalização; entender um pouquinho da história do diagnóstico, porque é muito diferente um paciente que chegou aqui sem história prévia de longa hospitalização e aquele que já tá há muitos anos em tratamento e sendo hospitalizado; conhecer os interesses e habilidades do paciente.

Cinco entrevistadas disseram realizar avaliaçóes informais, por meio de narrativas ou estruturadas pelo próprio serviço, ou seja, não validadas. Isso apareceu claramente na fala da TO4:

[...] uma avaliação mais informal mesmo, assim, no sentido de vê o que que a pessoa, é... as suas crenças em relação à morte, em relação a finitude da vida (TO4).

Três terapeutas ocupacionais utilizavam a Medida de Independência Funcional (MIF), avaliação padronizada que objetiva verificar o grau de independência do indivíduo, conforme explicou a TO7:

A gente tinha [...] um padrão que era a Medida de Independência Funcional porque a gente acabava pegando um pouquinho mais essa característica de permitir que o paciente continuasse independente, né, ou entâo mantivesse participação naquilo que precisava ser feito. Mas isso era a única avaliação validada que a gente tinha (TO7).

A TO13 levantou importante reflexão quanto a necessidade de discernimento na aplicação dos protocolos. Referindo-se a MIF, questionou sua utilização com pacientes cujos resultados eram esperados:

[...] Então... aqui a gente usa [...] a MIF. Embora, algumas vezes não faz muito sentido usar a MIF num paliativo que tá inconsciente, que a gente sabe que ela vai dar baixissimo (TO13).

Nesse sentido, Eva (2018) reforça a preocupação da TO13 ao reconhecer que para terapia ocupacional, como para qualquer profissional da área de reabilitação, é um desafio mensurar resultados em Cuidados Paliativos. A autora argumenta que é "improvável" encontrar-se resultados positivos na aplicação de avaliaçóes como a MIF, ou qualquer outra cujo foco seja a melhora da independência ou função. A autora reforça que pacientes com doenças avançadas apresentam deterioraçóes progressivas ao longo das intervençóes terapêuticas, por isso Eva (2018, p. 405) conclui:

Resultados significativos de terapia ocupacional serão aqueles com foco na capacitação de pacientes e cuidadores para que participem de ocupaçóes e papéis que continuam a ser importantes para eles.

Segundo Queiroz (2012), na abordagem dos cuidados paliativos, o terapeuta ocupacional visa promover conforto e qualidade de vida, auxiliar a pessoa e o cuidador no que diz respeito a lidarem com as dificuldades causadas pelas perdas funcionais, cognitivas, sociais e emocionais, bem como promover autonomia e/ou independência no desempenho ocupacional. Sendo corroborada pela teoria, a fala da TO3 abrangeu aspectos físicos, sociais e psicológicos em seus objetivos gerais:

Os objetivos, de maneira geral, porque ai é claro que cada paciente vai ter, né, especificidades, são: minimizar os efeitos adversos do processo de hospitalização e de adoecimento grave, né; auxiliar na adaptação da rotina; auxiliar no empoderamento, no sentido de auxiliá-los a compreender o que eles têm, por quais procedimentos vão passar, que a gente acha que isso diminui a ansiedade, né; e promover um ambiente mais acolhedor e humanizado, dentro do possivel. Esses seriam os gerais, e aí os específicos sáo de acordo com cada perfil (TO3). 
Promover a realização de atividades significativas foi um dos objetivos mencionados pela TO5:

Atividades significativas pra aquele paciente, que fossem importantes pra ele, naquele momento, [...] atividades significativas com a participação da família junto, tentando trazer o máximo de significado e de trocas sociais, né, entre os parentes, entre pessoas próximas que fossem realmente vinculadas aquele paciente, como também individualmente, com paciente, fazendo atividades (TO5).

Garcia-Schinzari, Sposito e Pfeifer (2013) respaldam os objetivos traçados pela TO5. Para as autoras o terapeuta ocupacional deve favorecer o desempenho das tarefas e atividades significativas na vida do indivíduo durante o percurso do tratamento, auxiliando na retomada do controle de suas práticas cotidianas, apesar das limitaçóes.

O desenvolvimento de atividades significativas foi intervenção unânime entre as entrevistadas, como no discurso da TO1:

Ele mexe o olho? Hum, então eu vou chegar lá e investigar o que que ele quer, o que que ele gosta, o que que eu posso trazer.' Que seja música, que seja uma meditação, que seja um cheiro, enfim. Vamos adaptar... Se ele tem o movimento do ombro a gente adapta de um jeito que ele consiga realizar algo que the traga alguma satisfação, $e$ eu acho que é isso (TO1).

Nessa linha, Gomes (2014) destaca as atividades significativas como meio de auxiliar o paciente no enfrentamento da doença e das condiçóes relacionadas à hospitalização e ao tratamento. A autora observa que, muitas vezes, mesmo em condiçóes adversas, o ser humano procura criar e fazer, por isso o terapeuta ocupacional deve intervir para manter e/ou desenvolver habilidades. Assim, o movimento do ombro ou de apenas um olho, bastaram para que os pacientes $\mathrm{da}$ TO1 fossem estimulados a realizarem atividades.

Conforme asseveram Othero e Ayres (2014), para pessoas com doenças muito graves, a realização de atividades significativas têm papel relevante, pois reafirma suas potencialidades e representa a possibilidade de os pacientes se manterem como sujeitos da própria história, o que confere sentido à vida.

Para De Carlo, Bartalotti e Palm (2004), o terapeuta ocupacional contribui para a promoção da capacidade funcional do sujeito hospitalizado, a fim de proporcionar maior autonomia e independência necessárias à manutenção do desempenho ocupacional, ou seja, de uma vida ativa. Berti e Carvalho (2014) definem autonomia como a capacidade que o ser humano apresenta de se autodeterminar, se traduz na liberdade de o sujeito agir de acordo com suas vontades. Garcia-Schinzari, Sposito e Pfeifer (2013) corroboram explicando que o terapeuta ocupacional auxilia na criaçáo de possibilidades de ampliaçáo da autonomia.

Cinco entrevistadas citaram que, em suas intervenções, preocupavam-se em estimular autonomia, dentre elas a TO2:

Então a gente pode fazer com o paciente, da forma que ele tenha mais autonomia, como as escolhas que ele precisar ter em relação à saúde dele, em relação às atividades de vida diária dele, as AIVDs até (TO2).

Dez participantes descreveram intervençôes para promoção de independência na realização de atividades, conforme narrou a TO1:

Tinham vários pacientes de ELA principalmente em fase terminal que eu consegui fazer adaptação, uma paciente queria ler, então a gente adaptou, ela só tinha o movimento do ombro, ela conseguia ler na UTI (TO1).

A TO1 exemplificou a definição de independência apresentada no documento da Associação Americana de Terapia Ocupacional (ASSOCIAÇÃO..., 2015), que considera independente o sujeito que desempenha atividades por si mesmo, ainda que necessite de um ambiente adaptado ou modificado, que use vários dispositivos ou estratégias alternativas.

De Carlo, Bartalotti e Palm (2004), amparam a intervenção desse profissional, ao ensinarem que a capacidade funcional do sujeito pode ser estimulada ou mantida pela indicação de adaptaçôes simples ou recursos de tecnologia assistiva.

Intervençóes para o controle da dor e outros sintomas por meio de medidas não farmacológicas foram mencionadas por oito entrevistadas. A TO12 contou:

A gente consegue trabalhar um pouco de controle de dor, né, técnica de relaxamento, é... orientação de posicionamento, ou auxiliar no posicionamento (TO12).

Alguns estudiosos condizem com o discurso da TO12 ao indicar técnicas de relaxamento, orientaçóes posturais e a realizaçáo de atividades (expressivas, de leitura, com música...) para o alívio da dor (PENGO; SANTOS, 2004; GARCIA-SCHINZARI; SPOSITO; PFEIFER, 2013).

A prevençáo de agravos e o posicionamento adequado, a fim de evitar contraturas, deformidades e úlceras de pressão, são referenciados por diversos 
autores da terapia ocupacional que indicam também a prescrição de equipamentos de tecnologia assistiva, conforme a necessidade do paciente (QUEIROZ, 2012; SILVA; OTHERO, 2010). Assim, ratificam as intervenções de seis entrevistadas que destacaram a importância do posicionamento adequado, como no discurso da TO1:

Aí ele pintava, ele cortava, ele escrevia, e ele era bem pequenininho assim, já tinha bem dificuldade de movimento... então a TO é fundamental pra isso assim, paciente acamado de longo prazo, paciente com deformidade, tem que fazer adaptação, sabe, a visão da TO, se não for a TO outro profissional não vai fazer... então a gente fez adaptação (TO1).

Tratando-se de uma doença ameaçadora da vida, o conforto, o controle de sintomas e o posicionamento adequado influenciam na melhora da qualidade de vida do indivíduo e proporcionam o aumento da autoestima. Dessa maneira, a intervenção deve favorecer a manutenção da qualidade de vida no período de internação (PAULINO; BIANCHIN, 2014; SILVA et al., 2014). A TO4, representando outras cinco entrevistadas, salienta:

Diminuindo dor, diminuindo o excesso de medicamentos, procedimentos invasivos, pra melhorar a qualidade de vida dele aqui dentro. [...] Pode ser que ela venha depois a melhorar, mas nesse mau prognóstico é você manter a qualidade de vida (TO4).

Além de possíveis prejuízos motores, devem ser evitadas perdas cognitivas e sensoriais, explorando as funçôes cognitivas e perceptivas, como: memória, raciocínio, pensamento abstrato, imagem corporal, percepção espaço-temporal; bem como realizar estimulação sensorial, que pode ser utilizada como forma de proporcionar conforto e controle de sintomas (ARINI, 2014; SOUZA et al., 2014).

Arini (2014) sugerem atividades para promover estímulos cognitivos: treino de memória; atenção; concentração; utilizando jogos, atividades com palavras, orientação no tempo e no espaço, confecção de calendário. Referente aos estímulos sensoriais, as autoras citam: promover estímulos agradáveis, a partir da história de vida de cada participante; toques; textura; cheiros; sabores; músicas; dentre outras. As indicações das autoras convergem com as falas de entrevistadas que citaram a estimulaçáo cognitiva e sensorial em suas práticas, conforme o discurso da TO1:

Ela tava com gastrostomia já, na verdade, então assim, fazia mais de um mês que aquela paciente não conseguia sentir nenhum sabor, nem nada, dieta nada de oral, né, porque ela tinha uma disfagia grave, mas a gente conseguiu, dai, a TO, a fisio e a fono juntos, fazer ela provar um pouco de chocolate. A gente colocou na boca e foi acompanhando, porque da nossa parte assim, foi um pouco da estimulação sensorial, um pouco de estimular o que ela tem de capacidades, de vontades de vida enfim (TO1).

Inocenti, Rodrigues e Miasso (2009) destacam outro ponto importante, principalmente no cuidado de paciente com doenças que ameaçam a continuidade da vida: família e/ou cuidador. As autoras ressaltam que a família constitui um dos núcleos centrais na formação de crenças, valores e conhecimentos do indivíduo. Com o adoecimento, toda a família sofre e sente as consequências do momento vivenciado. Diante da necessidade do cuidado, são necessários ajustes nas rotinas dos familiares, podendo gerar uma sobrecarga que restringe atividades, traz preocupaçôes, insegurança e isolamento, além de, mais das vezes, colocar o cuidador diante da falta de apoio e da morte.

Garcia-Schinzari, Sposito e Pfeifer (2013) ensinam que o acolhimento e a intervenção junto aos familiares ocorre com o objetivo de auxiliar na elaboraçáo do sofrimento; esclarecer quanto aos objetivos e possibilidades dos cuidados paliativos; fornecer um ambiente acolhedor; e, favorecer a comunicação e expressão de sentimentos, angústias e medos oferecendo escuta atenta. As palavras das autoras confirmam o depoimento da TO3 que abordou algumas dessas questóes:

E sempre a gente tá trabalhando no acolhimento aos cuidadores, né, porque quando o paciente vai agravando muito... se aproximando, mesmo, da terminalidade, a nossa açáa se volta bastante para o cuidador também, né, pra que ele possa entender esse processo (TO3).

Para Garcia-Schinzari, Sposito e Pfeifer (2013), auxiliar no empoderamento do paciente e familiares a respeito do diagnóstico e procedimentos, provendo orientaçôes quanto a realizaçáo de exames, procedimentos médicos, de enfermagem e/ou cirurgias e esclarecendo dúvidas, auxilia na minimização da ansiedade do paciente e seus familiares. Seis entrevistadas mencionam esse tipo intervenção, dentre as quais a TO7 refere:

[...] muitas vezes o paciente não entende o que o profissional tá falando, seja o médico, seja a nutricionista, seja enfermagem... e dai eles pedem pra gente traduzir. Em alguns momentos eu entrava junto e participava do diálogo que precisava acontecer e quando eles saíam eu retomava o diálogo com 
uma simplificação. Não é simplificação, porque se a gente fala simplificação dá a impressão que é uma coisa que não tem técnica, não énesse sentido. A gente trazia pro contexto daquela pessoa, né, a necessidade de colocar uma gastrostomia, sabe?! Essas coisas são muito dificeis da pessoa entender porque que tem que acontecer daquele jeito. Então agente tinha um processo muito de explicar o que que tava sendo feito com ele mesmo, porque ele tinha o direito, né (TO7).

$\mathrm{Na}$ fase final de vida, o tratamento deve mudar de foco, e o terapeuta ocupacional pode auxiliar no processo de despedida dos familiares, valorizando a vida remanescente do indivíduo e ajudando-o a viver o presente (FARIA; DE CARLO, 2015).

O terapeuta ocupacional se faz importante no processo de despedida, auxiliando no desenvolvimento de atividades para a confecção de produtos finais concretos, como presentes e cartôes para pessoas queridas; orientando os familiares a manterem comunicação e gestos de carinho com o paciente, ainda que estes estejam sedados; e realizando a mediação desta interação (GARCIA-SCHINZARI; SPOSITO; PFEIFER, 2013). Sete entrevistadas citaram o auxílio no processo de despedidas na atuação em cuidados paliativos. No depoimento da entrevistada TO3 é possível perceber intervençôes nesse sentido:

E ai aquelas questöes que eu falei pra vocês de fazer fechamentos, né. Então, tentar elaborar esses ciclos pelos quais eles estão passando; eles presenteiam alguns familiares e a gente tem que intermediar isso... Às vezes, escrever cartas, né, então a gente tenta auxiliar nesse contato e nesses fechamentos, enquanto eles não vêm a óbito (TO3).

O terapeuta ocupacional está habilitado a prestar assistência aos pacientes e familiares, a fim de favorecer o alívio das dificuldades causadas pelo adoecimento, evitar a perda da dignidade e os sentimentos de isolamento. As atividades com propósito envolvem a mente e o corpo tornando-se uma forma de expressão pessoal, criando um canal de relação entre a pessoa e seus familiares, um meio de manter a dignidade e a autonomia da pessoa (FIGUEIREDO, 2008).

\section{Considerações Finais}

Os objetivos do estudo foram: compreender a abordagem de cuidados paliativos adotada por terapeutas ocupacionais no cuidado de pessoas com doenças crônicas; e, conhecer a organizaçáo dos cuidados paliativos nos hospitais gerais de Curitiba. O estudo demonstrou que somente três hospitais gerais de Curitiba, assim classificados no CNES, possuíam terapeutas ocupacionais atuando no cuidado de pessoas em internação, no período de abrangência da pesquisa. Uma dessas instituiçóes ofertava cuidados paliativos em leitos específicos, apenas em uma das enfermarias, nos quais os terapeutas ocupacionais atuavam a partir de pedidos de consulta. Nos demais setores desse hospital e nas outras instituiçóes, os cuidados paliativos não estavam formalmente estruturados. Não obstante, as terapeutas ocupacionais entrevistadas utilizavam os princípios da abordagem em açóes paliativas com pessoas em cuidados de fim de vida. Portanto, a assistência não era ofertada através de equipe interdisciplinar, baseada em um plano de cuidado com objetivos comuns. A intervenção terapêutica ocupacional era realizada isoladamente ou compartilhada com outros profissionais da saúde, conforme o caso, cujo processo de trabalho foi relatado como multiprofissional, pela maioria das entrevistadas.

O tipo de avaliação utilizada dependia da organização do serviço de terapia ocupacional. Os objetivos da intervenção eram condizentes com os princípios dos cuidados paliativos, visavam o conforto e a dignidade do paciente. Constatou-se que a realização de atividades significativas era a principal intervenção, tendo sido citada por todas as participantes. Em segundo lugar, foram mencionados o acolhimento e as orientaçóes aos familiares e cuidadores, bem como a promoção de independência, seguidas pelo controle da dor e outros sintomas, além de processos de despedida. As profissionais referiram, ainda, a importância do auxílio no empoderamento do indivíduo, do posicionamento adequado, da promoção da autonomia e de estímulos cognitivos e sensoriais. Essas intervençóes vão ao encontro da promoção da qualidade de vida, bem-estar e manutençáo da vida ativa enquanto possível.

No que se refere às limitaçóes, sem dúvida a realização da pesquisa apenas em uma cidade pode náo ter refletido a realidade da maioria dos terapeutas ocupacionais que atuam em Cuidados Paliativos. Também pode ser considerada uma limitação a falta de questóes relacionadas às estratégias adotadas pelas entrevistadas para enfrentar o desconhecimento do papel do terapeuta ocupacional em Cuidados Paliativos pelos demais profissionais e o quanto esse problema afeta o processo terapêutico. Tampouco o estudo aprofundou questóes relacionadas ao tema da humanização, no contexto de trabalho das participantes.

Assim sendo, sugere-se que novas pesquisas sobre o tema abranjam maior território a fim de 
obterem amostras mais significativas da realidade da atuação do terapeuta ocupacional em Cuidados Paliativos, no Brasil. Propóe-se, ainda, que futuros estudos investiguem a dimensão e as causas do desconhecimento, por parte dos colegas da área saúde, inclusive gestores, a respeito do papel do terapeuta ocupacional. A conclusão desse estudo talvez possa versar nas pautas de eventos da profissáo, a fim de nortear estratégias da categoria.

Por fim, sabe-se que humanização e Cuidados Paliativos são indissociáveis, dessa forma sugere-se que novos estudos correlacionem a Política Nacional de Humanização $(\mathrm{PNH})$ com as intervençóes do Terapeuta Ocupacional em tal serviço.

Com este estudo, espera-se promover reflexóes sobre a realidade vivenciada pelos terapeutas ocupacionais na atuação junto às pessoas hospitalizadas, adotando a abordagem dos Cuidados Paliativos, e suscitar açôes que promovam mudanças positivas nesse cenário.

\section{Referências}

ARANTES, A. C. L. Q. Indicaçôes de cuidados paliativos. In: CARVALHO, R. T. de; PARSONS, H. A. Manual de cuidados paliativos. São Paulo: Academia Nacional de cuidados paliativos, 2012. p. 56-74.

ACADEMIA NACIONAL DE CUIDADOS PALIATIVOS - ANCP. Critérios de qualidade para os cuidados paliativos no Brasil. Rio de Janeiro: Diagraphic, 2006.

ARINI, T. S. Terapia Ocupacional em cuidados paliativos: práticas desenvolvidas no Hospital Premier (SP). In: OTHERO, M. B. (Org.). Cadernos de Terapia ocupacional em Oncologia. São Paulo: ABRALE, 2014. p. 7-10.

ASSOCIAÇÃO AMERICANA DE TERAPIA OCUPACIONAL - AOTA. Estrutura da prática da Terapia Ocupacional: domínio \& processo. Revista de Terapia Ocupacional da USP, São Paulo, v. 26, p. 1-49, 2015. Edição Especial.

BARDIN, L. Análise de conteúdo. Lisboa: Edições 70, 2011.

BERTI, V. C.; CARVALHO, S. M. O papel da bioética na promoção da autonomia do sujeito. In: DADALTO, L. Bioética e Direitos Antecipados de Vontade. Curitiba: Editora Prismas, 2014. p. 13-28.

BRASIL. Ministério da Saúde. Vigilância de Doenças Crônicas Não Transmissiveis. Brasília, 2015. Disponível em: <http:// portalsaude.saude.gov.br/index.php/o-ministerio/principal/ secretarias/svs/doencas-cronicas-nao-transmissiveis $>$. Acesso em: 24 jun. 2017.

BRASIL. Ministério da Saúde. Secretaria de Atenção à Saúde. Cadastro Nacional de Estabelecimentos de Saúde (CNES). Brasília, 2016. Disponível em: <http://goo.gl/ dUyGXd>. Acesso em: 02 nov. 2016.

DE CARLO, M. M. R. P.; BARTALOTTI, C. C.; PALM, R. C. M. Terapia Ocupacional em reabilitaçáo física e contextos hospitalares: fundamentos para a prática. In: DE CARLO, M. M. R. P.; LUZO, M. C. M. Terapia Ocupacional: reabilitação física e contextos hospitalares. São Paulo: Roca, 2004. p. 3-28.

DE CARLO, M. M. R. P.; QUEIROZ, M. E. G.; SANTOS, W. A. Terapia ocupacional em dor e cuidados paliativos: princípios, modelos de intervençáo e perspectivas. In: DE CARLO, M. M. R. P.; QUEIROZ, M. E. G. (Org.). Dor e cuidados paliativos: Terapia Ocupacional e Interdisciplinariedade. São Paulo: Editora Roca, 2008. p. 108-125.

EMMEL, M. L. G.; KATO, L. G. Conhecimento da Terapia Ocupacional pelo Estudante de Medicina. Cadernos de Terapia Ocupacional da UFSCar, São Carlos, v. 12, n. 2, p. 89-100, 2004.

EVA, G. Necessidade de pesquisa e evidências de Terapia Ocupacional em Cuidados Paliativos. In: DE CARLO, M. M. R. P.; KUDO, A. M. (Org.). Terapia Ocupacional em contextos hospitalares e cuidados paliativos. São Paulo: Payá, 2018. p. 399-411.

FARIA, N. C.; DE CARLO, M. M. R. P. A atuação da Terapia Ocupacional com mulheres com câncer de mama em cuidados paliativos. Revista de Terapia Ocupacional da Universidade de São Paulo, São Paulo, v. 26, n. 3, p. 418-427, 2015.

FIGUEIREDO, M. T. A. Prefácio. In: DE CARLO, M. M. R.; QUEIROZ, M. E. G. Dor e cuidados paliativos: terapia ocupacional e interdisciplinaridade. São Paulo: Roca, 2008. [s.p]

FONSECA, J. J. S. Metodologia da pesquisa cientifica. Fortaleza: Universidade Federal do Ceará, 2002. Disponível em: <http://www.ia.ufrrj.br/ppgea/conteudo/conteudo2012-1/1SF/Sandra/apostilaMetodologia.pdf>. Acesso em: 21 abr. 2016.

GARCIA-SCHINZARI, N. R.; SPOSITO, A. M. P.; PFEIFER, L. I. Cuidados paliativos junto a crianças $\mathrm{e}$ adolescentes hospitalizados com câncer: o papel da terapia ocupacional. Revista Brasileira de Cancerologia, Rio de Janeiro, v. 59, n. 2, p. 239-247, 2013.

GOMES, P. H. G. Terapia Ocupacional no centro de oncologia, hematologia e quimioterapia do Hospital da Força Aérea do Galeão. In: OTHERO, M. B. (Org.). Cadernos de Terapia ocupacional em Oncologia. São Paulo: ABRALE, 2014. p. 44-46.

INOCENTI, A.; RODRIGUES, I. G.; MIASSO, A. I. Vivências e sentimentos do cuidador familiar do paciente oncológico em cuidados paliativos. Revista Eletrônica de Enfermagem, Goiânia, v. 11, n. 4, p. 858-865, 2009.

INSTITUTO BRASILEIRO DE GEOGRAFIA E ESTATÍSTICA - IBGE. Pesquisa Nacional de Saúde. Rio de Janeiro, 2013. Disponível em: <ftp://ftp.ibge.gov. br/PNS/2013/pns2013.pdf>. Acesso em: 03 nov. 2016.

MACIEL, M. G. S. Definiçōes e princípios. In: CONSELHO REGIONAL DE MEDICINA DO ESTADO DE SÃO PAULO - CREMESP. Cuidado paliativo. Sáo Paulo: 
Conselho Regional de Medicina do Estado de São Paulo, 2008. p. 15-32.

MACIEL, M. G. S. Uniformização de nomenclaturas em cuidados paliativos. In: DADALTO, L. Bioética e Direitos Antecipados de Vontade. Curitiba: Editora Prismas, 2014. p. 47-65.

MELLO, M. A. F. et al. Processo avaliativo em Terapia Ocupacional. In: DE CARLO, M. M. R. P.; LUZO, M. C. M. Terapia Ocupacional: reabilitação física e contextos hospitalares. São Paulo: Roca, 2004. p. 74-98.

NUNES. L. V. O papel do psicólogo na equipe. In: CARVALHO, R. T.; PARSONS, H. A. (Org.). Manual de cuidados paliativos. São Paulo: Academia Nacional de cuidados paliativos, 2012. p. 337-340.

OTHERO, M.; COSTA, A. Conceitos, princípios e formação em cuidados paliativos. In: COSTA, A.; OTHERO, M. Reabilitação em cuidados paliativos. Lusodidacta: Loures, 2014. p. 23-35.

OTHERO, M. B.; AYRES, J. R. C. M. Resgate biográfico como estratégia de assistência a pacientes com condiçóes neurológicas muito graves. Revista de Terapia Ocupacional da USP, São Paulo, v. 25, n. 1, p. 80-87, 2014.

PAULINO, V. U.; BIANCHIN, M. A. Relato de experiência da Terapia Ocupacional no Serviço de Oncologia do Hospital de Base de Sáo José do Rio Preto (SP). In: OTHERO, M. B. (Org.). Cadernos de Terapia ocupacional em Oncologia. São Paulo: ABRALE, 2014. p. 39-43.

PARANHOS, T. Cuidados paliativos sob a perspectiva dos profissionais da saude. 2016. 24 f. Monografia (Bacharelado em Enfermagem) - Universidade de Santa Cruz do Sul, Santa Cruz do Sul, 2016. Disponível em: <https://repositorio. unisc.br/jspui/bitstream/11624/1352/1/Tatiana\%20 Paranhos.pdf>. Acesso em: 08 jul. 2018.

PENGO, M. M. S. B.; SANTOS, W. A. O papel do terapeuta ocupacional em oncologia. In: DE CARLO, M. M. R. P.; LUZO, M. C. M. Terapia Ocupacional: reabilitação física e contextos hospitalares. São Paulo: Roca, 2004. p. 233-255.

PINHEIRO, T. R. S. P. Avaliação do grau de conhecimento sobre cuidados paliativos e dor dos estudantes de medicina do quinto e sexto anos. O mundo da saúde, São Paulo, v. 34, n. 3, p. 320-326, 2010.
QUEIROZ, M. E. G. Atenção em cuidados paliativos. Cadernos de Terapia Ocupacional da UFSCar, São Carlos, v. 20, n. 2, p. 203-205, 2012.

RODRIGUES, L. F. Modalidades de atuação e modelos de assistência em cuidados paliativos. In: CARVALHO, R. T.; PARSONS, H. A. (Org.). Manual de cuidados paliativos. São Paulo: Academia Nacional de cuidados paliativos, 2012. p. 86-93.

ROESCH, S. M. A. Projetos de estágio do curso de administração: guia para pesquisas, projetos, estágios e trabalhos de conclusão de curso. São Paulo: Atlas, 1996.

SANTOS, A. M. S. Metodologia do Trabalho Cientifico. Salvador: Instituto Mantenedor de Ensino Superior Metropolitano S/C Ltda., 2010. Disponível em: <http:// intranet.ftc.br/upload/142901/203854_modulo\%20MTC. PDF>. Acesso em: 05 nov. 2016.

SILVA, R. F. A. et al. Terapia Ocupacional no Instituto do Câncer do Estado de São Paulo Octavio Frias de Oliveira (ICESP). In: OTHERO, M. B. (Org.). Cadernos de Terapia ocupacional em Oncologia. São Paulo: ABRALE, 2014. p. $25-28$

SILVA, R. F. A.; OTHERO, M. B. Plano de cuidados em equipe. In: OTHERO, M. B. Terapia Ocupacional: práticas em oncologia. São Paulo: Roca, 2010. p. 47-71.

SOUZA, M. E. B. et al. A intervenção da Terapia Ocupacional no Centro Pediátrico do Câncer do Hospital infantil Albert Sabin (Fortaleza-CE). In: OTHERO, M. B. (Org.). Cadernos de Terapia ocupacional em Oncologia. São Paulo: ABRALE, 2014. p. 84-87.

WORLD HEALTH ORGANIZATION - WHO. Key facts. Geneva, 2018. Disponível em: <http://www.who. int/news-room/fact-sheets/detail/palliative-care $>$. Acesso em: 03 jul. 2018

WORLDWIDE PALLIATIVE CARE ALLIANCE WPCA. Global Atlas of Palliative Care at the End of Life. WHO: England, 2014. Disponível em: <http://www.who. $\mathrm{int} / \mathrm{ncds} / \mathrm{management/palliative-care/palliative-care-atlas/}$ en/>. Acesso em: 03 jul. 2018.

VASQUES, T. C. S. et al. Cuidados paliativos no cotidiano de trabalho dos profissionais da saúde e de enfermagem. Revista de Enfermagem UFPE, Recife, v. 8, p. 3797-3785, 2014. Suplemento 2 .

\section{Contribuição dos Autores}

Andreia da Rosa Trevisana, Simone Reksua e Wagner Damian de Almeida foram responsáveis pela idealização da pesquisa, elaboraçáo do projeto, obtenção do TCLE, processamento da amostra, coleta, transcrição e análise de dados, redação do texto. Maria José Gugelmin de Camargo foi responsável pela idealização da pesquisa, elaboração do projeto, processamento da amostra, análise de dados, revisão final do texto. Todos os autores aprovaram a versão final do texto.

\section{Notas}

${ }^{1}$ O material apresentado é parte da pesquisa autorizada pelo Comitê de Ética em Pesquisa (CEP), do Setor de Ciências da Saúde da Universidade Federal do Paraná (UFPR), com CAAE nº 61630616.9.0000.0102. 